\title{
Why patients should keep their own records
}

\author{
Vernon Coleman Author, journalist and erstwhile general practitioner
}

\section{Author's abstract}

\section{Too many people now have access to confidential medical information. Patients are becoming jutifiably wary and the doctor-patient relationship is deteriorating. We can avert the developing crisis by allowing patients to keep their own medical records at home. This will ensure that confidentiality is respected and that patients continue to trust their doctors.}

There are many facets to the doctor-patient relationship but the basis of the whole relationship is trust. The doctor has to trust the patient to tell him everything that may be relevant. And the patient has to trust the doctor to treat that information as entirely confidential. Secrets are the essential currency of medical practice. Without access to intimate details of all kinds doctors cannot hope to make diagnoses.

Over the years doctors have succeeded in building up a collective reputation which gives them the same access to private information as priests, and which gives their surgeries and consulting rooms the same status as the confessional.

But just look at what has happened in recent years.

A decade or two ago a general practitioner interviewing a patient would scribble indecipherable notes on a scruffy piece of card. Only he would have access to that information and only he would be able to read it. If he needed specialist advice he would send a scribbled note to a hospital colleague.

Today the general practitioner has to write rather more legibly if his partners are to understand what he has written. He'll probably employ a secretary, a team of receptionists and a practice nurse: and have an attached health visitor and social worker.

At the hospital the specialist will be assisted by secretaries, administrators and a whole army of paramedical workers. All will expect open access to medical records.

Even more frightening than these developments, however, is the fact that a growing number of people with no interest at all in the health of individual

\section{Key words}

Patients; records; information; confidentiality; medical team; trust; ethics; computers; doctor-patient relationship. patients are finding that doctors' records are a valuable source of useful information.

The Department of Health and Social Security, for $\vec{\overrightarrow{ }}$ example, has established a right to obtain confidential $N$ information from general practitioners on national $\frac{9}{5}$ insurance certificates. That information is not treated as confidential medical information once the DHSS $\underset{3}{3}$ has got its co-operative hands on it. Indeed the information will be passed around within that administrative machine with only a token nod in the $\vec{c}$ direction of confidentiality.

Then there are the commercial employers who also want access to medical notes. Employers know very well that access to confidential information can give them an excellent idea of an employee's future medical potential. The man signed off work as 'depressed' is unlikely to be considered a suitable candidate for promotion. Once medical information has been obtained in this way it is likely to spread round any internal offices very quickly. Curiosity is a natural human emotion and news about Ethel's pregnancy or Joan's anxiety state is likely to spread rapidly.

In recent years the number of people likely to have access to information passed on in the surgery as 3 . confidential has increased quite dramatically. But still 8 more corporations, institutions and individuals are $₹$ likely to have access to those 'secrets' in the future.

People who borrow money from banks or building societies or who take out life insurance with major companies are likely to sign contracts giving permission for doctors to be contacted and medical o information released. Once information has been made $N$ available to one company it can then be passed on to $\mathrm{C}_{\mathrm{N}}$ any other company which shows an interest. Large 0 insurance companies and banks don't have any sense of confidentiality so the information, once it gets into their hands, becomes public property.

Just as worrying as the fact that raw information is 0 passed on, by the way, is the fact that such ${ }_{0}^{\circ}$ organisations are likely to be as interested in a doctor's $\stackrel{\mathbb{Q}}{\circ}$ conclusions as in his observations. So if a provisional $\mathbb{\nabla}$ diagnosis was made and entered on the medical records $\frac{\Omega}{\sigma}$ then that diagnosis is quite likely to be passed on from company to company, despite the fact that the 8 diagnosis was never justified or confirmed.

Social workers, clerks, employers, insurance 흘 
companies, banks - the list doesn't stop there. The police are also well aware that medical records are very useful. They frequently demand confidential information. Even when doctors refuse to pass on such information the police can still obtain it by contacting administrators, social workers or DHSS clerks.

What makes all this doubly frightening is the fact that more and more of these organisations and individuals are storing their own personal records on computers. That means that there is then almost no limit to the number of people who will have access to that information - information which was originally obtained, in complete confidence and trust, in the doctor's surgery. A scribbled note about a possible depressive tendency, a possible schizoid personality, a potential diagnosis of multiple sclerosis, cancer or venereal disease - this information stored on oldfashioned medical records is unlikely to be harmful but when translated into computer language and made available to any interested customers it can spell finis to a man's career.

And whatever promises may be made about computer secrecy the fact is that once information has been put into a computer by one agency other agencies will quickly find good excuses for getting that information out again. They will argue that the dissemination of confidential medical information helps them deploy services and analyse resources far more effectively. The information is there, they will point out, so it is unrealistic not to use it.

All this terrifies me for I firmly believe that only those directly concerned with the medical care of patients have any right to information that has been obtained in the surgery or the consulting room. If the current trend continues the consulting room will have more in common with the broadcasting box than the confessional - with the inevitable result that the number of people prepared to share their secrets with their doctors will shrink. Since secrets are the essential currency of medical practice the consequences will be disastrous.

The real irony in all this is that while just about everyone else in any sort of official or unofficial capacity seems to have open access to medical records the individual patient who is the subject of a set of medical notes still has no rights at all, and very little chance of ever seeing the medical records which concern him or her most of all.

And it seems to me that within this irony there lies the answer to our dilemma. Why not let patients keep their own medical records? We would thus in one simple move deny all administrators, policemen and non-medical personnel the chance of obtaining access to medical records while also giving patients the freedom to see exactly what had been written about them.

Patients could keep their medical records at home and take them along to the surgery or hospital whenever needed. This simple solution would release a whole army of expensive administrators from their onerous task of filing, storing and retrieving thousands of records. The cost of that service to the medical services must be measured in millions and the present complicated structure is so cumbersome that records often get lost, mislaid or misdirected. Today it can take months for a medical record envelope to find its way from one surgery to another. Allow patients to keep their own records and anyone moving house would simply take his or her medical records together with other important papers to their new doctors.

It is difficult to think of sound objections to such a simple scheme. Some doctors might argue that patients would be exposed to information that would worry them. But the truth is, of course, that patients wouldn't have to read their own notes - only look after them. Doctors might also argue that they would be limited in what they could write on notes. I don't think that's too much of an objection either. Indeed I suspect that too many doctors have become accustomed to putting value judgements on medical records. It is far too easy for a patient to be labelled as a 'nuisance', 'neurotic' or 'troublesome' merely because of a personality conflict between physician and patient.

Doctors wanting to use medical records for research will have to contact patients directly before they can obtain confidential information. This restriction might make some research work more difficult to organise but it will ensure that no research projects get under way without patients being consulted and their permission obtained. I don't think it is a bad thing if 'doctor convenience' takes second place to 'patient confidentiality'.

At St Mary's Maternity Hospital, Portsmouth, patients have been allowed to keep their hospital maternity notes for ten years now. They don't seem to have had too many problems there. Records have been kept in good condition, very few have been lost and much administrative time has been saved. Incidentally, many of the women concerned have admitted that they weren't able to understand what was on their notes. They were, however, happy to have their notes in their own possession.

Giving patients charge of their own records is the unavoidable answer to a growing confidentiality problem. Doctors will benefit because they will no longer have to store records and they won't have to fight for medical confidentiality against courts and politicians. They'll also have access to notes when they do house calls!

And patients will benefit, of course, because they will know that everything they tell their doctors will remain a secret.

Today we have reached a dangerous point. Many patients are wary of confiding in their doctors because they suspect that information passed on in secret will be made available to too many people. Without trust the medical profession cannot operate effectively. The only real answer is to hand over the care of medical records to patients. And it must be done without delay. 